\title{
Publishing Library Research
}

\begin{abstract}
Beginning with a brief examination of the nature of research, the article discusses how authors decide on the kind of journal to submit a manuscript to and how they write different kinds of articles for different kinds of journals. It next explores the range of journals available, discusses the functions of the editor and the refereeing process, and deals with the problem of unpublished dissertations and reports. Drawing on the author's experience as editor of The Library Quarterly, the article describes the process of publishing an article from the editor's receipt of a manuscript to its appearance in an issue of a journal.
\end{abstract}

$\mathbf{H}$ OW DOES AN AUTHOR DECIDE where to send an article for publication? How does a researcher write a paper aimed at a particular kind of publication? Where do reports of research submitted to journals fall down? What is the function of the editor with respect to the publication of research? What does the editorial process involve? What can potential authors expect from an editor?

Underlying these questions is a single problem regarded from two points of view. The points of view are those of the author and the editor, and the problem is the formal communication of research results to a scholarly or professional community.

In this paper I discuss only the publication of scholarly, research-based articles in journals. I neglect explicitly and completely the problems of publishing other kinds of articles and books whether described as professional, scholarly, or text. Moreover, the vantage point from which the paper is written is that of an editor in general, and the editor of The Library Quarterly in particular.

W. Boyd Rayward, now dean of the Graduate Library School, University of Chicago, was editor of The Library Quarterly from 1975 to 1979.

\section{The Nature of Research}

In passing, I would like to dismiss an idea sometimes expressed to me. It has to do with the nature of research. One does not design research with a view to publication in a particular kind of journal. One can present the results of research in a variety of ways: as a monosyllabic discourse intelligible to a high school football team, for example, or as a complex series of equations covering half a dozen pages that are intelligible only to a handful of scholars scattered in remote corners of the globe.

The research process itself, however, is always designed to investigate a problem in such a way as to obtain evidence that will support one solution over a potentially infinite number of conceivable solutions. It is a process of reducing alternatives; of cutting speculation to the quick; of asking questions and finding testable answers to them.

The questions can be more or less interesting, perceptive, important, practical, or theoretical; and the process of finding answers can be more or less rigorous, can raise more or fewer questions in its turn, and can lead to more or less definite, complete, believable, and useful answers. Yet this is all the process involves: asking inves- 
tigable questions, devising ways of finding objective evidence for answering them, and evaluating the evidence obtained to see how good it is and how far it goes in providing appropriate answers. It is a flexible process. There is no formula for doing research. It involves creativity and imagination in thinking up questions and methodologies, and analytic rigor or incisiveness in evaluating evidence.

If research is regarded as a process of asking questions and finding evidence to support answers, it need not be thought of as a mysterious or forbidding or exclusive process although some research will be all three because of the nature of the prior knowledge necessary to understand it, or because of the originality of the investigative approach employed or the complexity of the problem studied. Complex methodologies and elaborate statistical procedures are directed at assuaging the cultivated skepticism of expert judgment when it causes readers to ask of authors: How can you say that? How do you really know that? How sure can you be of what you say? It should be possible for authors to be able to translate for the general reader the rationale for and the significance of their research designs and statistical analyses of data into plain English prose. Authors who cannot do this as occasion requires may be justly accused of not having properly understood what they have done.

\section{ASSESSING COMPLETEd RESEARCH}

Having completed research of some kind, how does one decide how to write it up and then where to send it for publication? Three factors should enter into the decision: (1) an evaluation of the importance of what one has done; (2) a determination of the nature of the audience or audiences one wants to reach; and (3) the requirements of the journals that one judges might be interested in the papers one may prepare. Of course, considerations of these factors are not mutually exclusive.

In arriving at a dispassionate, carefully considered assessment of the value or significance of one's work, one examines it in the light of certain questions: How important and complex was the problem investigated? How close to matters of practice was it? Were the results fairly complete, firm, and reliable, or were they merely tentative and suggestive? What do their implications seem to be? Into what professional or scholarly fields do they ramify? Was the methodology more interesting than what it was used for or revealed?

One can go on to ask: To whom do I wish to communicate my work? To as many as possible throughout the whole profession? To those working in my own area of practice or of research in librarianship? To those in a related discipline of which I consider myself also to be a member? To a limited scholarly community able to assess my work on its merits as research? Or to fellow workers in particular kinds of library environments? To a general, intelligent, wellinformed community at large for whom my work may be of interest?

Answers to these questions lead one to decide on the kind of journal one may wish to publish in: a popular, practical professional journal or a general or specialized scholarly one; a scholarly journal in a related field or a journal of a general nature. The choice of an audience and the consequent choice of a journal will determine the kind of article one will try to write and the distance one will try to achieve from the detail of the research in one's account of it. The latter point is important.

\section{KINDS OF ARTICLES}

Having come to some synthesis of answers to the questions just raised, a researcher asks: What are the kinds of articles that I might try to write?

There could be an account that takes pains to establish comprehensively the links of the work reported to related work, that provides sufficient data to enable replication of its results, or independent corroborative analysis of them. Such an account would lead to a paper with a full scholarly apparatus of footnotes, charts, tables, and so on. One might submit it to The Library Quarterly or College \& Research Libraries.

A brief technical note about one or more aspects of what was done or discovered could be submitted to the Journal of the American Society for Information Science, or The Communications of the American Society for Computing Machinery, or the 
Journal of Library History. Such notes would keep close to the specifics of the research, and one would try to place such articles in scholarly journals in one's own or related fields.

One could prepare a popular account stressing the interesting aspects of the problem one investigated from a professional or practical point of view and the nature of the results obtained for a regional library journal or Library Journal or American Libraries.

Or one could prepare a general account in which are examined the implications of one's work for higher education, or policy formulation, or local government, or the management of science; this kind of article might appear in Science, Minerva, American Scholar, or Educational Record. Such general articles as these are removed to greater or lesser degrees from the details of research.

Frequently, a single piece of research is made the basis of several papers of the kinds indicated above in order that its results may reach, quite appropriately, different special or general audiences.

Having decided on the nature of the article or articles one wants to write and having identified possible journals of interest, the next step is obvious but all too infrequently followed. One goes to the journals and examines them. This examination will show exactly what kinds of articles the journals carry (general, theoretical, practical, scholarly, popular), how long the articles may be, what format they are expected to be in (a question of headings, form and location of footnotes and references, whether charts and tables and abstracts are used, and so on), and to whom manuscripts are to be sent.

Sometimes such matters are dealt with explicitly in a statement of editorial policy and instructions to contributors; but sometimes inferences are necessary from what has appeared in recent issues.

Some journals will simply return manuscripts that do not meet minimum formal style requirements rather than go through the refereeing process and suffer the delay caused by the author then reworking the manuscript to meet style requirements. Others will return articles to be put into style after the refereeing process has taken place and the manuscript has been provisionally accepted.

\section{RANGE OF JOURNALS}

Whatever one decides about the kind of article one wants to write, there is a wide range of journals to receive one's work. This is not always appreciated. Given the number and variety of journals, there is no reason why a paper of any competence should not be published.

Let me illustrate without in any way being comprehensive. There are the ALA journals which are devoted to library functions, kinds of libraries, and library clienteles. Samples of the first are Library Resources \& Technical Services (LRTS), RQ, and Journal of Library Automation; of the second, College \& Research Libraries, Public Libraries (the old PLA Newsletter), and School Media Quarterly; and, of the third, Top of the News.

There are journals of other library associations or societies whose work is more or less directly related to libraries: Bulletin of the Medical Library Association, Special Libraries, Notes, Journal of Education for Librarianship, the Journal of the American Society for Information Science, American Archivist, and the Papers of the American Bibliographical Society are examples here.

There are journals published by or in association with library schools, such as The Library Quarterly or Journal, Library History, or Drexel Library Quarterly.

Some important journals are published by regional associations or state institutions such as state libraries. Examples here are Illinois Libraries, PNLA Quarterly, and Southeastern Librarian. Though some of the local or regional journals are devoted to gossipy news and public relations, many, such as those I have mentioned among others, publish general articles as well as articles of regional interest. Some like Illinois Libraries have several issues within a year dedicated to directory information or to special subjects, and contributions to the latter kinds of issue are usually by invitation from a special guest editor, but most have issues in which space is available for unsolicited material.

There are several widely circulated popular journals: Library Journal, American Li- 
braries, and Wilson Library Bulletin. These tend to devote much of their space to news, features, and columns and to have different policies about accepting unsolicited manuscripts.

Apart from local or national journals is a group often overlooked. This group comprises international journals both of a special and a general nature. Examples of the latter are Libri, Unesco Journal of Information Science, Librarianship and Archives Administration (formerly Unesco Bulletin for Libraries), and International Library Review. Examples of the former are International Forum for Information and Documentation, Information Processing and Management (formerly Information Storage and Retrieval), Fontis Artis Musicae (International Association of Music Libraries), and INSPEL: International Journal of Special Libraries.

Recently there has emerged a group of specialized independent or commercial library journals, such as The Journal of Academic Librarianship, On-Line Review, and Library Research; and there is a positive spate of new specialist journals from Haworth Press: Collection Management, Serials Librarian, Public Library Quarterly, Behavioral and Social Sciences Librarian, Library and Archival Security, Cataloging and Classification Quarterly, and others advertised but not yet issued.

Finally, there are journals whose primary focus is not on library or related matters but for which such matters may be of occasional interest: Children's Literature, Journal of Popular Culture, or Communications of the American Society for Computing Machinery, for example.

Historical articles could be submitted not only to The Library Quarterly or Journal of Library History but to the American Historical Review or regional historical society journals. Articles on women in librarianship could be submitted to feminist journals such as Signs.

The identification of potential outlets for an article can be a matter of considerable ingenuity, and some thought can lead an author to stimulating discoveries about journals and audiences. A useful guide to the variety of library-related journals is the FID List of Library, Documentation and Archives Serials. ${ }^{1}$ A comprehensive and thoughtful survey of American library journals from a historic perspective appears in J. Periam Danton's "The Library Press." 2

All the journals mentioned will publish papers in which the results of research are reported and many of them have similar interests and will be in competition for the same articles. Nevertheless, they tend to have different style requirements, and potential contributors should become sensitive to their special subject focuses and the kinds of audience they attempt to reach, matters to which inspection of several copies gives most of the necessary clues.

\section{THE ROLE OF THE EDITOR}

Having decided to send an article to a particular journal, what can the author expect from the editor? What does the editor do when an article appears on the desk? In the pages that follow I will tend to draw examples from and comment on practices at The Library Quarterly.

At the outset I should say that most editors of scholarly journals are not interested in preliminary inquiries from authors about submitting articles. They prefer receiving a completed manuscript. They expect that manuscripts will arrive on their desks unannounced. If they are like me, they wait eagerly for the day's mail to see what it will bring. All a letter of inquiry can do is suggest that an article is likely to be in scope; but even this is difficult to ascertain without a full text to go on. The author's best preparation is to examine issues of the journal he or she is interested in before deciding to send in an article.

In the case of certain widely circulating popular journals, however, a preliminary letter to sound out the editor's interest is probably wise, and often these kinds of journals will suggest this practice to potential contributors in a notice published in the journal. Otherwise such letters waste everyone's time.

The editor's first decision is an answer to the question: Is the article in scope? An editor worth his or her salt does not ask as the first question: Who is the author? Anyone, for example, can submit a manuscript to The Library Quarterly. Of concern to me as editor is the quality of the article, nothing else. Articles come in from practitioners 
in the field, library school faculty, and students and scholars in nonlibrary fields; but I have no interest in who contributors are, what their institutional affiliations may be or whether they come decked out in a doctorate or a library directorship or in more humble academic or professional weeds.

In deciding if an article is in scope, the editor must have in mind a clear and steady idea of what kind of a journal he or she is editing. Let me give a general description of The Library Quarterly prepared by one of my predecessors to be sent to potential contributors:

Since its inception in January $1931, L Q$ has been dedicated to the publication of reports of research, but discussions of problems and issues in librarianship and solid descriptive articles are also accepted if they are based on evidence and the synthesis of data rather than on conjecture and unsupported personal opinion. Descriptions of purely local, institutional, and operational experiments are acceptable if they lend themselves to broad generalization and adoption.

Until recently, The Library Quarterly was the only really general, entirely scholarly American library journal though now the new Library Research shares many of its major objectives. As to scope, let me give a description that I myself prepared some time ago:

Among The Library Quarterly's areas of interest are the organization and management of libraries, the analysis and use of subject literatures, all aspects of bibliographical organization and control, studies of users' needs, reading, publishing, and most problems of information dissemination and use.

Having decided that an article is in scope, the editor decides to have it refereed or to reject it at once. The editor rejects outright manuscripts whose subject and treatment are inappropriate to his or her journal. I have been sent short stories, for example. Some time ago I received a delightful, rather rhapsodic effusion about the effects of the New York Public Library on a sensitive mind. I read such pieces because they are usually interesting, and then reject them, as delicately as I can, as completely out of scope.

Other manuscripts are no less clearly unacceptable. One of the first I received upon becoming editor was a one-page abstract of a dissertation about children's books in Mexico that the author thought I would be delighted to publish. I wrote back suggesting that the author draw a proper article from the dissertation, first looking at some issues of The Library Quarterly to see what kinds of articles we publish. I received a three-page abstract by way of reply and summarily rejected it.

I should say that the decision to proceed to the refereeing process or not, at least in the case of The Library Quarterly, is based on the principle of slightest doubt. If there is the slightest doubt about a paper, I send it to referees; and about 95 percent of articles received are refereed. All articles published are refereed.

\section{REFEREEING}

Refereeing is a process of submitting a paper to impartial, expert critical judgment. The refereeing process is crucial. On it depends the quality of research that is published, and it is as a result of this process that scholars lay claim to their reputations (and journals to their role and stature) in a field. I stress here that I speak of scholarly reputation as opposed to professional reputation which may turn on work in ALA, for example, or the innovative management of a library.

No aspect of a paper is too minor for the referees' scrutiny, but mostly they attempt to assess the importance of the problem studied, the appropriateness of the methodology used, and the validity of the conclusions drawn from the data.

The refereeing process allows editors to transcend the inevitable limitations of their own knowledge and understanding, and to find peers for a paper regardless of its subject; that is, individuals who know what has already been written on the subject, who can assess the relevance and potential impact of the article under study, and who have special methodological expertise or professional experience against which to evaluate it.

Editors choose as referees those whom they believe to be expert in the subject or methodology of a particular paper. Referees are usually drawn from the professional and academic communities at large or from editorial boards made up of members of 
these communities. They tend to accept refereeing assignments as part of their general professional responsibilities and usually obtain no reward but the knowledge of their contribution to the quality of the articles published in the field. Usually they are sent guidelines to assist them in their assessment of a paper and a form on which to respond. Ziman has described the referee as the "lynchpin about which the whole business of science is pivoted." 3

Referees are no less, perhaps they are more, important in a professional field like librarianship, where there is little or no consensus about the nature or value of a characteristic scholarship and where the research base is broad and ill-defined.

Refereeing is usually anonymous. The referees are not given the authors' names, nor are the authors given the names of the referees. There has been debate as to the value of anonymity. ${ }^{4}$ It can be argued that attempts to preserve the anonymity of authors are unlikely to be successful.

A good editor will choose as referees for a particular paper those most competent to judge it. Those most competent to judge it, however, will be active in the area of the paper's subject and likely, therefore, to be able to guess or, from internal clues, to know definitely who the author is. Their own anonymity, as far as the author is concerned, may allow them to give rein to professional prejudice or jealousy. Released from the responsibility of having to defend or account for their views, the argument runs, they can be nasty or capricious. Those who are less likely to know who the author is are also likely to be less competent in their evaluation of a paper's significance or contribution.

These kinds of problems are seriously discussed in science, but fortunately, given the nature of the field, they can generally be discounted in librarianship, though an editor should always be alert to the possibility of such difficulties arising.

In the case of The Library Quarterly I usually choose two referees for a paper, but I have sent a paper to as many as four or five, and, indeed, have returned papers to one or more referees for further assessment in light of the comments of other referees.
On the basis of the referees' reports, the editor decides whether to accept or reject the paper. This itself is not simple because the opinions of referees often conflict. I had one case recently where one referee thought that the paper involved should be shortened to a few polemical pages and submitted to another journal; another thought that tightened up a bit and more carefully argued, the paper should be accepted; and a third, proceeding to sit on the fence, said cautiously that it was not without merit.

The range of decisions that can be made are: (1) to accept; (2) to accept provisionally pending certain specified revisions; (3) to suggest general, usually major revision and resubmission; or (4) to reject.

An editor can reject a paper in several ways: outright, perhaps by a form letter, or by suggesting other places where it might be submitted. Sometimes editors reject papers without giving reasons for their decision, in order perhaps to avoid the possibility of disagreeable wrangling. My own practice is to indicate in a general way why I have decided that a paper is unsuitable. This seems an appropriate response to a colleague who has, in a sense, asked for judgment. Moreover, the editor has the referees' comments to offer, and these can be used to indicate that the decision is not personal, is not the editor's "fault" as it were. Of course, the editor has the final say, even if only by silence.

\section{REVISION}

Acceptance of manuscripts is usually contingent on revision. I used to be astonished at how badly written or presented or developed most papers, especially nonhistorical papers, are in our field.

The reasons for this are many, no doubt, but one of the major ones is a lack in librarianship of a tradition of cumulative research, a tradition that in the sciences and social sciences has tended to prescribe the form papers take. Our research is so various, so fragmented, draws on so many methodologies and disciplines that scholars are bound to be confused as to what is appropriate in the presentation of their work. Moreover, often a writer publishes only one major work drawn from a dissertation or thesis, and so does not through prac- 
tice acquire expertise in conducting and reporting research.

I might say that recently a paper was published in The Library Quarterly, the preparation of which began two Library Quarterly editors ago with an entire dissertation. The process of revision was slow and was carried out over half a dozen versions of the paper. While this is an extreme case, two or three versions are not unusual.

While revision ultimately leads to an article judged substantively acceptable by the referees, it is also a process of meeting standards of scholarly communication and, indeed, of intelligible communication generally. Resolved here are problems in logic, the presentation of evidence, and the textual organization of the paper.

In asking for revisions or even in rejecting a paper, the editor draws on the referees' reports in various ways. Sometimes they are returned to the author verbatim though as I indicated earlier, usually anonymously; sometimes they are excerpted in a general letter; sometimes they serve as the basis for detailed commentary by the editor on the text of the paper. In all of this, the editor is perhaps more closely involved with the author's text than is the case in many better-established scholarly fields.

Editing in librarianship, at least in my own view and in terms of my practice at The Library Quarterly, is rather more than providing a switching mechanism between a manuscript, the referees' judgments of quality, and the technical aspects of publishing. I see it as partly a collegial and partly an educational process, a dialogue which culminates in the editor finally giving a firm "yes, acceptable" or "no, unacceptable" to the author.

\section{ThESES, Dissertations, AND REPORTS}

Doctoral dissertations, master's theses, and reports of funded research and demonstration projects of various kinds, in which much of the research in the field is recorded, present a range of problems for author and editor alike in the preparation of articles drawn from them.

The dissertation is a record of expertise achieved as well as embodying a contribution to our knowledge. In the dissertation the student must show that he or she has read a considerable body of relevant literature and has understood and employed correctly appropriate research techniques. The dissertation chronicles false as well as correct moves. It is a document which must satisfy a committee.

In an article, evidence of accumulating expertise is not required. An article is not a report of an educational experience. It sets out a problem, a method of investigation, and results. To achieve the apparent directness, characteristic brevity, and simplicity of an article from the painstaking discursiveness of most dissertations requires a careful reassessment of what was of most importance in what was done and the sacrifice of many pages of prose that were often completed by the student at a great cost of suffering. What in all of the apparatus of a dissertation is its contribution to knowledge is the question that must be answered.

It is a matter of regret to me that many who graduate with the doctorate or prepare fine master's theses or papers do not submit themselves to this discipline. As an editor, I see as one of my major tasks the encouragement of such persons to meet a serious professional and academic obligation to report what they discover.

Similar comments can be made about research reports which are usually prepared to satisfy the requirements of funding agencies. The format of these reports is sometimes prescribed by the funding agencies themselves. Reports are usually detailed and discursive, and, where there have been interim or progress reports, either subsequent reports do not stand fully alone or they incorporate much that has already appeared in the earlier or preliminary form. They are not only reports of research, they are accounting documents in which the expenditure of sums of money of various amounts is defended.

In this respect, they are not necessarily dispassionate so much as drawn up clearly on the one hand to justify the expenditures made and frequently to make evident, on the other, the need for future funding of a continuation of the research reported. Like dissertations and theses, then, the formal functions of research reports are complex and different from the functions of articles. The comparative brevity of the articles 
drawn from them (though some reports, like some dissertations and theses, are revised and published in extenso as books) is symptomatic of the difference, and in preparing articles from research reports, authors must ask themselves similar questions to those asked by students revising theses and dissertations, and they must submit themselves to similar disciplines.

It is important to realize that dissertations and reports of the kind mentioned here are not formally published. They have not been through the general sifting, evaluative process that is now commonly accepted as necessary for achieving "public knowledge" in a discipline. They have not been prepared for and submitted to general professional scrutiny and approval beyond particular universities or funding bodies. They are usually neither refereed in the professional community at large, nor reviewed by it upon production, though dissertations must satisfy examiners and reports must be accepted by funding agencies.

In terms of adding to our knowledge, they tend to represent a job half done. As useful as bibliographical tools and retrieval systems of various kinds are in allowing us to become aware of the existence of, and to have access to, the text of dissertations and reports, the contribution of dissertations and reports to professional knowledge is not complete until they are published either as articles or books.

\section{COMMON DEFICIENCIES OF .PAPERS}

What are the major problems that appear in papers? They are just what one might expect and are covered in every textbook on research methodology and in every course on the same subject: poor problem definition, methodological inadequacies (especially in sampling), badly constructed instruments such as questionnaires, erroneously applied statistical procedures, inappropriate inferences from data, and what, in a general way, I call bad flow (the progression of a paper's argument, its logical organization, and unfolding).

What makes a good paper? Avoiding the problems I have just identified, of course. But the question can best be answered by a series of other questions that the author should address to his or her paper, and that the editor most certainly will address to it.

Is an interesting problem clearly identified? Why is it of interest? Is it placed in an appropriate context both in terms of the subject area of which the problem is part and in terms of relevant literature and research? Does the author make clear what the research was intended to accomplish, and, related to this, does he or she indicate at the end how successful the research was and what the nature of the reservations are that one must bear in mind in understanding what was accomplished?

Is an appropriate methodology described in sufficient detail for results deriving from it to be intelligible to a technically competent reader? Are sufficient data presented to allow the reader to understand what was found? Are the data properly discussed and analyzed? Does the paper flow clearly and logically from one point to another? That is to say, is there an easily grasped organization to the major sections or intellectual components of the paper?

It is at this point that I want to return to my rather bold claim that sophisticated research designs and highly complex technical methodologies can be dealt with in plain English prose. I always ask myself, no matter how technical a paper is, if the author has indicated in terms intelligible to a reasonably well-informed (but technically incompetent) reader such as myself, what was found as a result of the methodology and what is the significance of the findings.

I recently returned a paper that presented an abstract mathematical model asking for just such explanations. It should be possible for us all, no matter how mysterious the middle sections of a paper may be, to understand quite clearly its beginning and end. Nor should one interpret this as a kind of condescension. The explanations should be thorough and thoughtful and as lengthy as necessary.

\section{SCHEDULING FOR PUBLICATION}

Having decided to accept an article, the editor has then to schedule it for publication. This can be easy if he or she has few articles and works from issue to issue or if articles are published strictly in order of acceptance. As a matter of policy, I try to make each issue of The Library Quarterly 
balanced in terms of subjects and methodological approaches represented in the articles. In this way, I think I indicate partly my own view of librarianship and partly what kind of a periodical I think The $\mathrm{Li}$ brary Quarterly should be.

There are problems in the heterogeneity that results, and the suggestion has been made by members of my editorial board and by other colleagues that The Library Quarterly ought to be more precisely focused. My own view is that a number of good specialist library journals already exist, and I have indicated earlier something of the variety of these journals, all of which publish research to a greater or lesser degree. But to repeat myself, there is no general scholarly journal in the U.S. other than The Library Quarterly which can accommodate long articles over the whole field of librarianship supported by a full scholarly apparatus.

\section{Copy EdITING}

Once articles are assigned to an issue, they have to be prepared for the press. This is the process of copy editing. Some editors will have to do this for themselves. Fortunately for me, The Library Quarterly is one of over forty journals published by the University of Chicago Press, one of the largest scholarly publishers in the English-speaking world.

Copy editing is carried out at the press by experts. Their purpose is to prepare the manuscript so that technically it conforms to the style and standards of the press.

The manuscript is returned to me from the copy editors marked up so that the printers will know exactly how it is to appear in type and also with questions to the authors and to me. Because of the size and range of journal publishing done by the press, the process of copy editing is carried out with an almost unbelievable professional skill. Footnotes, tables, headings, and the text itself are all examined in the minutest detail. Inconsistencies, contradictions, obscurities of style or reference that I miss, my assistant misses, the author has missed, or that we did not know existed until they were pointed out are caught, questioned, or corrected by the copy editors.

One of the reasons for the stature of The
Library Quarterly as a scholarly journal is this extraordinary care that goes into its physical, textual preparation which, through the copy editors, extends far beyond the scope of the things my colleagues on the editorial board and I do. I make the major decisions about what will be published and how the text generally will appear. The copy editors attend to all the minutiae, the myriad detail that must be exactly right if the highest standards of excellence in the presentation of the text are to be met.

Once copy edited, the manuscript has to be checked. Most journals are set in type after copy editing and galley proofs of articles are pulled and sent to authors for checking. Because of our publication schedules we do not send out galleys. I answer what questions I can for the copy editors and then return the copy-edited manuscripts to the authors who answer the questions asked by me or the copy editors and check the text of their manuscript to see that they approve of any changes introduced by us. They do not see the copy again until it is published.

\section{PUBlication}

The Library Quarterly galleys are checked in my office by my assistant and a student hired for the purpose. One reads from the copy-edited manuscript, the other checks the galley. The corrected galley is returned to the press with any questions that occur to us now that we see the paper in type. The galley is then returned to the printer who pulls page proofs. Page proofs are then checked to see that the corrections marked on the galleys have been made by the printer. Once the page proofs are corrected and passed, final printing begins. We receive an inspection copy of The Library Quarterly before the loose pages are bound into the covers. This allows us to make sure everything looks all right. At this stage we once caught an error in volume numbering for an issue! Then binding is completed and the journal mailed out to subscribers.

\section{CoNCLUSION}

Let me summarize what I think the functions of the editor are in the publication of research in librarianship. The editor is both a guardian of, and an agent to assist in, 
scholarly professional communication.

Most simply put, the editor's function is to work with authors as closely as necessary to achieve acceptable papers. First, the editor must be alert to research in progress or completed and encourage the formal reporting of that portion of it of interest to the journal he or she edits. Second, the editor must encourage the fullest, most thorough and authoritative evaluation possible of the reported research through the refereeing process. Third, the editor must guide authors in meeting the highest standards of scholarly communication in the presentation of the reported research.

Editors are anonymous sorts of people.
They should be supportive, critical, sensitive to what is being presented, and they should be aware of and insist on the highest possible standards. They react to what others do. In a most important sense their work is not creative. The cumulative record of the journal they guide, usually for a limited period of years, represents standards, provides models, may influence aspirations, may even help define a field. But ultimately good research depends on the imagination, the training, and the dedication to scholarly ideals of researchers and the authors they become when they carry out their obligation to communicate the results of their work. The editor is there to help.

\section{REFERENCES}

1. Fédération International de Documentation, List of Library, Documentation and Archives Serials, FID 532 (4th ed.; The Hague: FID, 1975).

2. J. Periam Danton, "The Library Press," Library Trends 25:153-76 (July 1976). Ed. note: See also "Library Periodicals in Review," a special section edited by Joel M. Lee, Serials Review 5:7-39 (July/Sept. 1979); and "The
Literature of Librarianship and Information Science," edited by George S. Bobinski, Drexel Library Quarterly 15 (Jan. and April 1979).

3. J. M. Ziman, Public Knowledge (Cambridge: Cambridge Univ. Pr., 1968), p.111.

4. See, for example, A. J. Meadows, ed., The Scientific Journal (London: Aslib, 1979), passim. 